\title{
Virtual Reality (VR) simulation for laparoscopic cholecystectomy: the process of validation and implementation in the surgical curriculum outlined.
}

\author{
Schijven MEP. Virtual Reality (VR) simulation for laparoscopic cholecystectomy: the \\ process of validation and implementation in the surgical curriculum outlined. Universiteit \\ Leiden. [S.I.]: [s.n.]; 2005. 179 pagina's. ISBN: 90-9019048-1.
}

In dit proefschrift is ingegaan op de noodzaak tot het ontwikkelen van specifieke laparoscopische trainingsprogrammás voor de huidige opleidingsassistent chirurgie. De doelstelling ervan: het uiteenzetten van het proces van een stapsgewijze, gestructureerde validatie en implementatie in het chirurgische curriculum van de Xitact LS500 VR laparoscopische cholecystectomie- simulator.

Allereerst is naar de mening van assistenten over de stand-van-zaken betreffende trainingsaspecten in de minimaal invasieve chirurgie (MIC) gevraagd. De studie laat zien dat alle assistenten ( $100 \%$ !) het belangrijk vinden dat ze aan het einde van hun chirurgische opleiding in staat zijn om de basale laparoscopische procedures te kunnen verrichten (de diagnostische laparoscopie, de laparoscopische cholecystectomie en de laparoscopische appendectomie). Eén op de tien assistenten geeft aan dat hij of zij denkt hiertoe niet in staat te zullen zijn. Assistenten chirurgie met een bijzondere interesse in de gastrointestinale of oncologische chirurgie zijn vaker geïnteresseerd in het zelfstandig uitvoeren van de meer geavanceerde laparoscopische verrichtingen. Deze groep assistenten verwacht niet dat ze die verrichtingen aan het einde van hun opleiding ook daadwerkelijk zelfstandig uit kan voeren. De discrepantie wordt toegeschreven aan het feit dat men "[...] niet genoeg kans ziet om als eerste operateur de verrichting uit te voeren" en "[...] er niet genoeg van deze geavanceerde ingrepen plaatsvinden in het ziekenhuis van opleiding". Geconcludeerd wordt dat slechts $17.8 \%$ van de assistenten chirurgie in Nederland verwacht in staat te zijn zelfstandig de door hem of haar geambieerde geavanceerde laparoscopische procedure(s) uit te voeren aan het einde van de chirurgische opleiding. Specifieke laparoscopische trainingsprogramma's gericht op de chirurgische assistent geïnteresseerd in het zelfstandig uitvoeren van de verrichtingen kunnen, mits goed opgezet en geëvalueerd, wellicht een uitkomst bieden.

Vervolgens wordt een onderzoek gepresenteerd naar de waarde van de Advanced Dundee Psychomotor Tester (ADEPT) als objectief scoringssysteem voor psychomotore taakverrichting. Het bleek dat het ADEPTsysteem in staat is aangeboren talent voor psychomotore verrichtingen in te schatten en dat door het repeteren van de taken de uitvoering verder verbetert.

Hierna is de validiteit van de Xitact LS500 laparoscopische cholecystectomie VR-simulator onderzocht. De simulator werd gezien als een bruikbaar instrument voor het aanleren en meten van laparoscopische taakuitvoering. Het bleek dat zowel de expert als de minder geoefende chirurg gelooft in de toepassing van de simulator als trainingsinstrument voor de procedure van de laparoscopische cholecystectomie ('face validiteit').

Om uitspraken te doen over de construct validiteit van de Xitact LS500 laparoscopische cholecystectomie VRsimulator (er is logischerwijs een verschil in score tussen expert chirurgen en onervaren chirurgen op de simulator) is nagegaan of de clip-en-knip taak op de simulator de klinische procedure van het clippen en knippen van de ductus cysticus en arteria cystica goed weergeeft. Aangetoond werd dat zowel experts als beginners de clip-enknip simulatie van grote waarde achten in het trainen van chirurgische assistenten. Simulatiescores zijn, zo bleek, afhankelijk van de mate van klinische ervaring met de gesimuleerde procedure. Ook bleek dat de gemiddelde scores van beide groepen, logischerwijs, hoger werden naarmate de simulatie vaker verricht werd.

Vervolgens wordt een onderzoek beschreven waarin het thema van selectie van de laparoscopische chirurgische assistent aan bod kwam en de concurrente validiteit van de Xitact LS500 laparoscopische cholecystectomie 


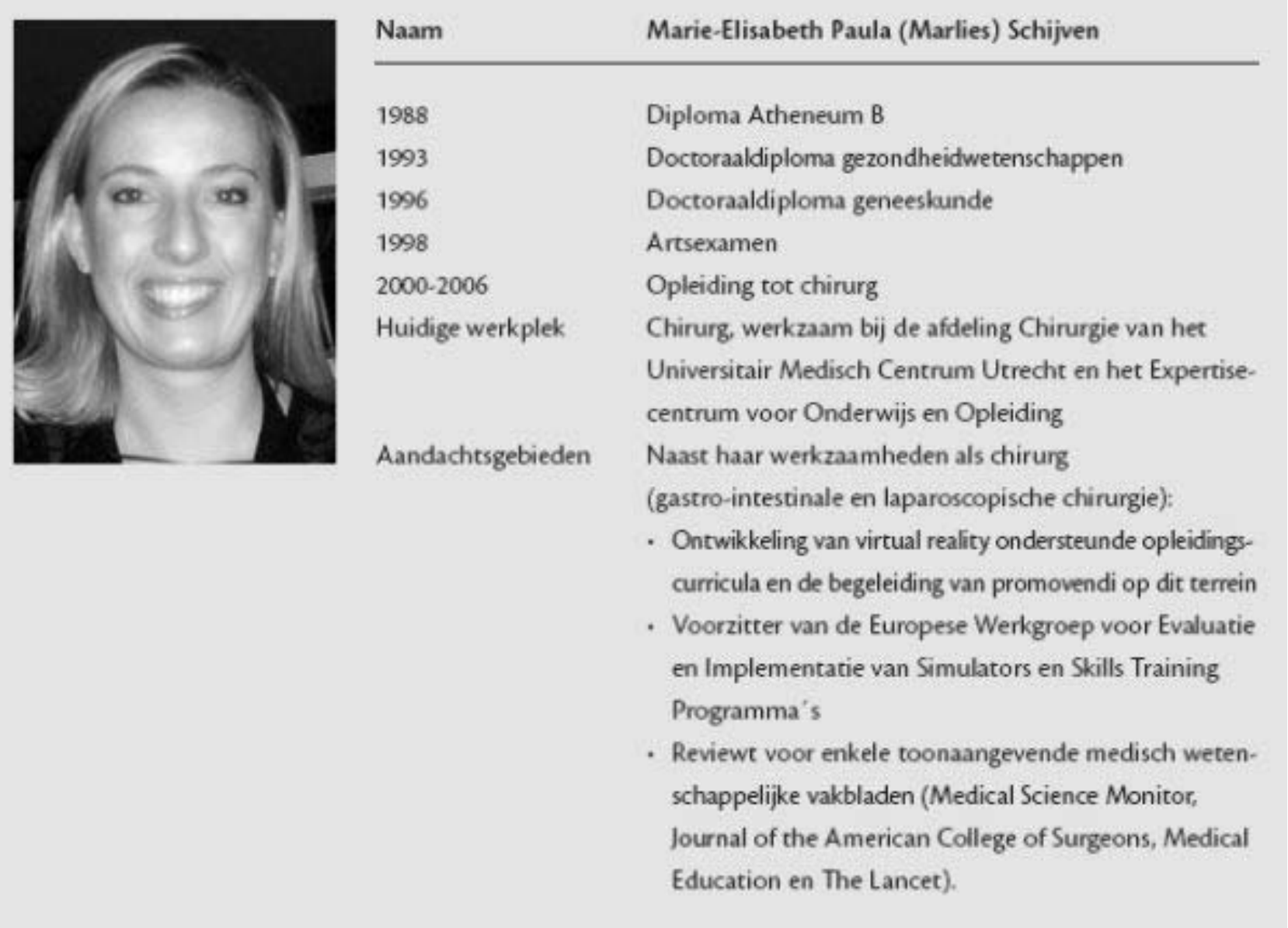

VR-simulator werd onderzocht. Deze concurrente validiteit werd onderzocht door individuele Xitact resultaatsscores te vergelijken met de resultaten van een andere testopstelling, welke gericht is op het in kaart brengen van iemand's psychomotore aanleg. Deze al eerder gevalideerde psychomotore testopstelling zou een betekenisvolle aanwinst kunnen zijn bij de selectie van aankomende chirurgen. Hoewel het onderwerp 'selectie van assistenten' verdere discussie behoeft, correleren de gecombineerde testresultaten van de Space Relation- test en de Abstract Reasoning-test in deze onderzoekssetting met de individuele testresultaten op de Xitact clip-enknip simulatie. De concurrente validiteit van de Xitact LS500 laparoscopische cholecystectomie VR-simulator met de Space Relation test en de Abstract Reasoning test wordt onderschreven door dit onderzoek. Op basis van leercurves van de clip-enknip simulatie, uitgevoerd op de Xitact LS500 laparoscopische cholecystectomie VR-simulator, bleek het mogelijk vier elkaar uitsluitende patronen te identificeren, die de taakverrichting en het leerproces op de Xitact simulator categoriseren. Categorie 1 betreft een groep hoog getalenteerde assistenten van wie de procedures weinig meer verbeteren door herhaalde simulatietraining (16.7\%). Groep 2 betreft een groep gemiddeld getalenteerde assistenten, die beter worden in het verrichten van procedures en stabieler in uitvoering zijn gedurende repetitieve simulatietraining $(30 \%)$. Groep 3 betreft een groep gemiddeld getalenteerde assistenten van wie de procedures wel verbeteren door simulatietraining, maar die meer moeite hebben om een stabiele prestatie te verkrijgen gedurende de repetities ('uitschieters naar beneden' of 'een slechte dag') (33.3\%). Groep 4 tenslotte betreft assistenten die laag getalenteerd zijn en niet blijken te verbeteren gedurende repetitieve simulatietraining $(20 \%)$. Deze studie laat zien dat het niet correct is om leercurves te construeren en extrapoleren op basis van de verrichtingen van slechts één persoon. Het blijkt mogelijk om profielen van verschillend getalenteerde assistenten te abstraheren met behulp van VRsimulatie. De meeste assistenten blijken gevoelig voor verbetering, en dus voor training, in laparoscopische taakuitvoering met behulp van herhaalde VR-simulatietraining. Geconcludeerd wordt dat VR-simulatie in de chirurgie inmiddels een levensvatbaar concept is. Feitelijk is het een ontwikkeling die de eerste kinderziektes voorbij is. Mits gevalideerd, zijn het systemen die erom 
vragen op een structurele wijze ingezet en ingebed te worden in het opleidingscurriculum van de toekomstige geneeskundig specialist. VR-simulatoren bieden, als geen andere onderwijsmethode, de mogelijkheid tot het veilig, herhaald en op gestructureerde wijze trainen van assistenten in een klinische procedure met de mogelijkheid tot een objectieve beoordeling van de uitvoering ervan. VRsimulatiemodulen zijn er heden-ten-dage in velerlei uitvoeringen, gericht op het trainen van een veelheid aan klinische procedures.

Simulatiemodules zijn niet alleen beschikbaar voor toekomstige (laparoscopische) chirurgen: tevens zijn er modules voor het trainen van toekomstige (vaat)- chirurgen, cardiologen, pulmonologen, urologen, radiologen, anaesthesiologen, orthopaeden, oogartsen, keel- neus- en oorartsen, gynaecologen en gastro-enterologen. Ook beroepsgroepen als operatiekamer assistenten, anaesthesieverpleegkundigen en nurse practitioners, betrokken bij invasieve klinische procedures, kunnen profiteren van deze technologie. Het is belangrijk om overzicht te houden op de ontwikkelingen en te discussiëren over de wijze waarop deze simulatoren op een kosteneffectieve wijze kunnen worden geïmplementeerd in het medisch (specialistisch) onderwijs. Het skills-laboratorium, waar simulatoren naast elkaar ingezet en onderhouden kunnen worden, elkaar aanvullen en ingepast kunnen worden naast andere vormen van vaardigheidsonderwijs lijkt hiervoor de ideale omgeving. Een dergelijke opstelling zou in principe toegankelijk moeten zijn voor iedere (chirurgische) assistent in opleiding. Bij voorkeur zou toegang verleend moeten worden via vormgegeven, gevalideerd cursorisch onderwijs. In navolging van de ontwikkelingen in de luchtvaartindustrie en de training van piloten, zullen VRsimulatoren in de nabije toekomst onmisbaar worden in de opleiding en wellicht ook behulpzaam bij de selectie en re-certificering van chirurgen en andere snijdende heelkundige specialismen. 